\title{
Author Correction: Microfluidic Enrichment Barcoding (MEBarcoding): a new method for high throughput plant DNA barcoding
}

\author{
Morgan R. Gostel, Jose D. Zúñiga, W. John Kress, Vicki A. Funk \& Caroline Puente-Lelievre
}

Correction to: Scientific Reports https://doi.org/10.1038/s41598-020-64919-z, published online 26 May 2020

This Article contains a typographical error in the Materials and Methods section under the subheading 'Microfluidic PCR amplification for library preparation and clean-up' where,

"Microfluidic PCR amplification was carried out on a Fluidigm Access Array at the Center for Conservation Genomics at the Smithsonian Institution's Conservation Biology Institute (Washington, District of Colombia, USA) and followed the protocol for "4-Primer Amplicon Tagging 48.48 Access Array IFC" outlined in the Fluidigm Access Array User Guide (Fluidigm PN 100-3770, San Francisco, California, USA).”

should read:

"Microfluidic PCR amplification was carried out on a Fluidigm Access Array at the Center for Conservation Genomics at the Smithsonian Institution's Conservation Biology Institute (Washington, District of Columbia, USA) and followed the protocol for "4-Primer Amplicon Tagging 48.48 Access Array IFC" outlined in the Fluidigm Access Array User Guide (Fluidigm PN 100-3770, San Francisco, California, USA).”

\begin{abstract}
(c) (i) Open Access This article is licensed under a Creative Commons Attribution 4.0 International License, which permits use, sharing, adaptation, distribution and reproduction in any medium or format, as long as you give appropriate credit to the original author(s) and the source, provide a link to the Creative Commons license, and indicate if changes were made. The images or other third party material in this article are included in the article's Creative Commons license, unless indicated otherwise in a credit line to the material. If material is not included in the article's Creative Commons license and your intended use is not permitted by statutory regulation or exceeds the permitted use, you will need to obtain permission directly from the copyright holder. To view a copy of this license, visit http://creativecommons.org/licenses/by/4.0/.
\end{abstract}

(C) The Author(s) 2020 